\title{
The terminal portion of leptospiral immunoglobulin-like protein LigA confers protective immunity against lethal infection in the hamster model of leptospirosis
}

\author{
Éverton F. Silva ${ }^{\mathrm{a}, \mathrm{b}}$, Marco A. Medeiros ${ }^{\mathrm{c}}$, Alan J.A. McBride ${ }^{\mathrm{a}}$, Jim Matsunaga ${ }^{\mathrm{d}, \mathrm{e}}$, \\ Gabriela S. Esteves ${ }^{c}$, João G.R. Ramos ${ }^{\text {a }}$, Cleiton S. Santos ${ }^{\text {a }}$, Júlio Croda ${ }^{a}$, Akira Homma ${ }^{c}$, \\ Odir A. Dellagostin ${ }^{b}$, David A. Haake ${ }^{\mathrm{d}, \mathrm{e}}$, Mitermayer G. Reis ${ }^{\mathrm{a}}$, Albert I. Ko ${ }^{\mathrm{a}, \mathrm{f}, *}$ \\ ${ }^{\text {a } G o n c ̧ a l o ~ M o n i z ~ R e s e a r c h ~ C e n t r e, ~ O s w a l d o ~ C r u z ~ F o u n d a t i o n, ~ B r a z i l i a n ~ M i n i s t r y ~ o f ~ H e a l t h, ~ S a l v a d o r, ~ B r a z i l ~}$ \\ ${ }^{\mathrm{b}}$ Biotechnology Centre, Federal University of Pelotas, Pelotas, Brazil \\ c Bio-Manguinhos, Oswaldo Cruz Foundation, Brazilian Ministry of Health, Rio de Janeiro, Brazil \\ ${ }^{\mathrm{d}}$ Veterans Affairs Greater Los Angeles Healthcare System, Los Angeles, CA, USA \\ ${ }^{\mathrm{e}}$ Department of Medicine, The David Geffen School of Medicine at UCLA, Los Angeles, CA, USA \\ ${ }^{\mathrm{f}}$ Division of International Medicine and Infectious Disease, Weill Medical College of Cornell University, NY, USA
}

Received 18 April 2007; received in revised form 15 May 2007; accepted 23 May 2007

Available online 14 June 2007

\begin{abstract}
Subunit vaccines are a potential intervention strategy against leptospirosis, which is a major public health problem in developing countries and a veterinary disease in livestock and companion animals worldwide. Leptospiral immunoglobulin-like (Lig) proteins are a family of surface-exposed determinants that have Ig-like repeat domains found in virulence factors such as intimin and invasin. We expressed fragments of the repeat domain regions of LigA and LigB from Leptospira interrogans serovar Copenhageni. Immunization of Golden Syrian hamsters with Lig fragments in Freund's adjuvant induced robust antibody responses against recombinant protein and native protein, as detected by ELISA and immunoblot, respectively. A single fragment, LigANI, which corresponds to the six carboxy-terminal Ig-like repeat domains of the LigA molecule, conferred immunoprotection against mortality $(67-100 \%, P<0.05)$ in hamsters which received a lethal inoculum of $L$. interrogans serovar Copenhageni. However, immunization with this fragment did not confer sterilizing immunity. These findings indicate that the carboxy-terminal portion of LigA is an immunoprotective domain and may serve as a vaccine candidate for human and veterinary leptospirosis.
\end{abstract}

(C) 2007 Elsevier Ltd. All rights reserved.

Keywords: Leptospirosis; Subunit vaccine; Leptospiral immunoglobulin-like protein; Recombinant protein; Immunity; Antibodies; Hamsters

\section{Introduction}

Leptospirosis, a spirochetal disease, is a major public health problem worldwide. The disease is considered to be the most widespread zoonosis in the world [1,2] due to the pathogen's ability to induce chronic carriage in the kidney tubules of a wide range of wild and domestic animals $[1,3,4]$.

\footnotetext{
* Corresponding author at: Centro de Pesquisas Gonçalo Moniz, Fundação Oswaldo Cruz, Rua Waldemar Falcão, 121, Candeal, Salvador, 40296-710 Bahia, Brazil. Tel.: +55 713176 2302; fax: +55 7131762281 .

E-mail address: aik2001@med.cornell.edu (A.I. Ko).
}

Transmission to humans occurs during direct contact with animal reservoirs or an environment contaminated by their urine. Infection in 5-15\% of the clinical infections causes life-threatening manifestations such as acute renal failure and pulmonary haemorrhage. Fatality among severe cases is more than 5-40\% [4,5]. Leptospirosis is recognized to be an emerging infectious disease in developed countries due to outbreaks associated with sporting events [6] and adventure tourism [7-9], and the increasing number of cases found among travellers [10], participants of recreational activities [11] and inner-city populations [12]. However, leptospirosis imparts its greatest disease burden in developing countries 
[13]. More than 500,000 cases are reported each year [2], of which the majority occur among rural subsistence farming populations [1,3,4] and urban slum dwellers [14-16]. Current control measures have been uniformly ineffective in addressing leptospirosis in these settings $[13,16]$.

Vaccines represent a potentially cost-effective approach to preventing neglected tropical diseases, such as leptospirosis, and promoting poverty reduction [17]. An effective leptospirosis vaccine would conceivably prevent human disease through immunization of at-risk populations or blockade of transmission through immunization of animal reservoirs. Leptospirosis is an important veterinary health problem in domestic cattle, pigs and dogs $[1,4,18]$. Commercially available vaccines, consisting of heat or chemically inactivated leptospires, protect hamsters from lethal infection although protection from sub-lethal infection of the kidneys is incomplete $[19,20]$. Yet despite widespread vaccination with whole-cell inactivated vaccines, leptospirosis remains prevalent in domestic animal populations [4,21]. Several problems with current vaccine approaches limit their use in humans. Whole-cell vaccines produce only short-term immunity, requiring administration semi-annually. Both residual media components and leptospiral lipopolysaccharride (LPS) have been associated with adverse reactions $[1,3,4]$. The variability of the LPS carbohydrate epitopes accounts for the serovar specificity of LPS-based vaccines; there is little crossprotection against infection with the vast majority of other leptospiral serovars [22-24].

Outer membrane proteins (OMPs) are attractive alternatives to whole-cell inactivated vaccines because of their antigenic conservation across leptospiral species and serovars. A number of transmembrane and lipoprotein OMPs have been shown to be surface-exposed and expressed during infection of the mammalian host [13,25]. In the form of purified recombinant proteins, the porin OmpL1 and the lipoproteins LipL41 and LipL32, also known as hemolysis-associated protein 1 , have not been found to be immunoprotective $[26,27]$. However, when expressed as membrane proteins in E. coli, OmpL1 and LipL41 exhibit synergistic immunoprotection in the hamster model of leptospirosis [27]. Immunization of gerbils with an adenovirus construct encoding LipL32 improved survival to $87 \%$ after challenge with serovar Canicola compared to $51 \%$ survival in control-immunized gerbils [26]. More recently, immunization of gerbils with a pcDNA3.1 DNA vaccine construct containing the lipL32 gene has also been found to provide partial protection from lethal challenge [28].

The genes encoding the leptospiral immunoglobulin-like (Lig) repeat proteins were discovered by screening bacteriophage lambda expression libraries with human and equine leptospirosis sera [29-32]. The Lig proteins belong to a family of bacterial immunoglobulin-like (Big) repeat domain proteins that includes intimin and invasin, the host colonization factors expressed by enteropathogenic E. coli and Yersinia spp., respectively. Three Lig proteins have been described, designated LigA, LigB, and LigC. LigA consists of 13 Ig-like imperfect tandem repeats, while $\mathrm{LigB}$ and $\mathrm{LigC}$ have $12 \mathrm{Ig}$-like tandem repeats followed by large $\sim 80 \mathrm{kDa}$ carboxy-terminal domains that do not contain Ig-like repeat domains. Virulent forms of L. interrogans serovar Copenhageni and L. kirschneri serovar Grippotyphosa express LigA and LigB with sequence-identical amino-terminal regions, while in both strains the locus encoding LigC is a pseudogene [30]. A mouse-adapted strain of L. interrogans serovar Manilae expresses $\operatorname{LigA}$ and a truncated version of $\operatorname{LigB}$ which includes the tandem Ig-like repeat domains but not the large carboxy-terminal non-repeat domain [29].

Lig proteins are surface-associated moieties [30] and may serve as targets for bactericidal responses. Recently, Lig proteins have been shown to bind fibronectin [33], indicating that they may serve as adhesins. Immunization with Lig proteins may conceivably induce pathogenesis-blocking responses. Kozumi et al. demonstrated that immunization of $\mathrm{C} 3 \mathrm{H} / \mathrm{HeJ}$ mice, which are genetically deficient of tolllike receptor 4 [34], with either form of $L$. interrogans serovar Manilae-derived LigA protected against lethal challenge [29]. However, mice are significantly less susceptible to leptospiral challenge than hamsters, gerbils or guinea pigs, which are the generally accepted animal models for leptospirosis [4]. More recently, Palaniappan et al. evaluated the immunoprotective role of recombinant LigA protein in hamsters and found that all LigA-immunized animals survived infection with L. interrogans serovar Pomona [35]. However, $57-88 \%$ of the control-immunized animals survived, which received the same infecting dose $\left(10^{8}\right.$ bacteria) indicating that the challenge strain was of low virulence. Furthermore, the study did not have the statistical power to demonstrate that LigA immunization conferred significantly improved survival in independent experiments. Therefore there is not as of yet, sufficient evidence to conclude that recombinant Lig proteins confer protection in the hamster model.

In this study, we produced recombinant Lig protein fragments and characterized the immune response induced by immunization with these fragments in hamsters. We found that a LigA fragment conferred protection against lethal challenge in an infection model that used a highly virulent $L$. interrogans strain ( $\mathrm{LD}_{50}, 45$ bacteria) and showed that the carboxy-terminal unique region of LigA, corresponding to the last six Ig-like repeat domains, contained an immunoprotective domain. To our knowledge, this is the first conclusive evidence demonstrating that immunization with a purified, recombinant protein confers protection in the standard Golden Syrian hamster model for leptospirosis.

\section{Material and methods}

\subsection{Leptospira strains and serum samples}

L. interrogans serovar Copenhageni strain Fiocruz L1130 , isolated from a patient during an outbreak of leptospirosis in the city of Salvador, Brazil [14,36], was culti- 
vated in Ellinghausen-McCullough-Johnson-Harris (EMJH) liquid medium (Difco Laboratories) at $29^{\circ} \mathrm{C}$. Culture growth was monitored by counting in a Petroff-Hausser chamber (Fisher) and dark-field microscopy as described [4]. The clinical isolate was passaged four times in hamsters and three times in vitro. Seed lots were then prepared and stored in $25 \%$ glycerol at $-70{ }^{\circ} \mathrm{C}$. Frozen aliquots were thawed and passaged a further four times in EMJH liquid medium prior to use in experiments to determine the $\mathrm{LD}_{50}$ in hamsters and challenge experiments.

Convalescent serum samples were obtained from patients with laboratory-confirmed leptospirosis during hospitalbased surveillance in Salvador, Brazil [14]. Sera from healthy control individuals were donated by the state blood bank. Leptospirosis was confirmed by the microagglutination test (MAT) as previously described $[4,37]$. The use of subject sera for these experiments was approved by the Internal Review Boards of the Oswaldo Cruz Foundation and New York Presbyterian Hospital.

\subsection{Cloning, expression and purification of recombinant $6 \times$ His tagged Lig proteins}

The proteins $\operatorname{LigA}$ and $\operatorname{LigB}$ (Fig. 1) were identified as previously described [30]. The LigANI fragment of LigA, corresponding to nucleotides $1873-3675$ of the ligA sequence (GenBank accession number NC_005823 Region: 533414-537088), the LigBNI fragment of LigB, corresponding to nucleotides $1873-3773$ of the $\operatorname{lig} B$ sequence and the LigBrep fragment of $\mathrm{LigB}$, corresponding to nucleotides 391-1948 of ligB (GenBank accession number NC_005823 Region: 526395-532067), were selected for expression as recombinant proteins. PCR was used to amplify the target sequences from genomic DNA purified from $L$. interrogans Copenhageni Fiocruz L1-130 with the following primer pairs, LigANI-F 5'-CAATTAAAGATCGTTATACG-

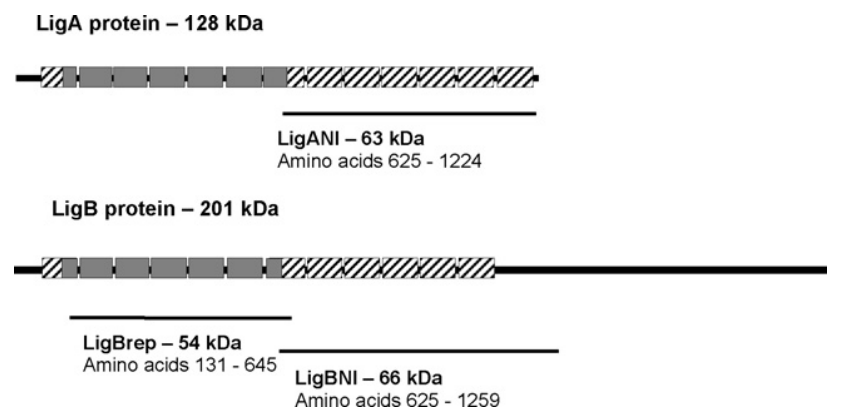

Fig. 1. Schematic representation of LigA and LigB proteins and recombinant fragments. Boxes represent bacterial immunoglobulin-like (Big) tandem repeat domains ( 90 amino acids). Amino acids 102-630 (Big domains 2-6 and part of 7) of $\operatorname{LigA}$ and $\operatorname{LigB}$, the region with $100 \%$ amino acid sequence identity between these two proteins, are represented as grey boxes. The C-terminal Big domains of LigA (amino acid position 631-1224) and LigB (amino acid position 631-1119) have lower amino acid sequence identity $(38 \%)$ and are represented as hatched boxes. Lines represent the three recombinant fragments, LigANI, LigBrep and LigBNI that were cloned and expressed.
ATAC, LigANI-R 5'-GGTCTAGATTATGGCTCCGTTTTAATAGAGG; LigBNI-F 5'-CACCTCCTCTAATACGGATATT, LigBNI-R 5'-TTACACTTGGTTTAAGGAATTAC; LigBrep-F 5'-ATGGGACTCGAGATTACCGTTACACCAGCCATT, LigBrep-R 5'-ATTCCATGGTTATCCTGGAGTGAGTGTATTTGT. The resulting 1802 bp (LigANI) $1900 \mathrm{bp}$ (LigBNI) and $1558 \mathrm{bp}$ (LigBrep) PCR products were cloned into the plasmid pET100-TOPO (Invitrogen) for expression of Lig recombinant proteins with an $\mathrm{N}$ terminal $6 \times$ His tag. All plasmid constructs were confirmed by DNA sequencing with an ABI 3100 sequencer (Applied Biosystems). E. coli BL21(DE3)Star transformants containing the Lig constructs were cultured at $37^{\circ} \mathrm{C}$ to mid $\log$ phase and expression was induced by isopropyl- $\beta$-Dthiogalactopyranoside (IPTG), $1 \mathrm{mM}$ final concentration. The cells were harvested by centrifugation, resuspended in column buffer ( $8 \mathrm{M}$ urea, $100 \mathrm{mM}$ Tris, $300 \mathrm{mM} \mathrm{NaCl}, 5 \mathrm{mM}$ imidazole, $\mathrm{pH} 8.0)$, and disrupted by sonication $(3 \times 1 \mathrm{~min}$ pulses; Sonics \& Material Inc.). The soluble fraction was recovered $(10,000 \times g, 10 \mathrm{~min})$ and loaded onto $\mathrm{Ni}^{2+}$-charged chelating sepharose columns (Qiagen). Columns containing bound protein were washed with 10 volumes of column buffer, then $6 \times$ wash buffer ( $6 \mathrm{M}$ urea, $100 \mathrm{mM}$ Tris, $300 \mathrm{mM}$ $\mathrm{NaCl}, \mathrm{pH}$ 8.0) containing $5 \mathrm{mM}$ imidazole for the first three washes and increasing to $10 \mathrm{mM}$ imidazole for the remaining washes. His-tagged proteins were eluted from the column with wash buffer containing $250 \mathrm{mM}$ imidazole. An extended stepwise dialysis procedure was used to remove urea and imidazole and to promote protein refolding of the recombinant fragments. Dialysis was performed in 18 steps over a period of 6 days at $4{ }^{\circ} \mathrm{C}$ with $100 \mathrm{mM}$ Tris, $300 \mathrm{mM} \mathrm{NaCl}$, $\mathrm{pH} 8.0$ buffer that contained decreasing concentrations of urea $(6-0 \mathrm{M})$ in each step. After the stepwise procedure, the purified protein fragment was dialyzed against phosphatebuffered saline (PBS, $\mathrm{pH} 7.2$ ) at $4{ }^{\circ} \mathrm{C}$ for $24 \mathrm{~h}$ and stored at $-20^{\circ} \mathrm{C}$ until use. The Bradford assay (Bio-Rad) was used to determine protein concentration of purified preparations.

\subsection{Protein gel electrophoresis and immunoblotting of recombinant proteins}

For one dimensional sodium dodecyl sulphate-polyacrylamide gel electrophoresis (SDS-PAGE), samples were solublized in sample buffer $(62.5 \mathrm{mM}$ Tris hydrochloride (pH 6.8), 10\% glycerol, 5\% 2-mercaptoethanol, 2\% SDS) and separated on a discontinuous buffer system (Mini Protean 3, Bio-Rad). Proteins were transferred to nitrocellulose membranes following the manufacturer's instructions (Mini transblotter, Bio-Rad). Membranes were incubated in blocking buffer (0.05 M TBS (pH 7.4), 0.05\% (v/v) Tween 20 (TBST), $5 \%(\mathrm{w} / \mathrm{v})$ non-fat dried milk) overnight at $4{ }^{\circ} \mathrm{C}$. After washing in TBST $(3 \times 5 \mathrm{~min}$ per wash), membranes were incubated with sera (diluted 1:200 in TBST) from leptospirosis patients and healthy control individuals for $1 \mathrm{~h}$ at room temperature. Membranes were washed with TBST ( $4 \times 5$ min per wash) and incubated for $1 \mathrm{~h}$ at room tempera- 
ture with anti-human IgG conjugated to alkaline phosphatase (Sigma-Aldrich), which was diluted $1: 10,000$ in TBST. Membranes were washed in TBST $(3 \times 5$ min per wash) and TBS before colour development using an NBT/BCIP solution following the manufacturer's instructions (Bio-Rad).

\subsection{Hamster immunization}

Female Golden Syrian hamsters with 4-5 weeks of age were immunized subcutaneously with Lig recombinant protein fragments in Freund's complete adjuvant on day 0 and a second immunization of antigen in Freund's incomplete adjuvant on day 14. Immunization was performed with a range of recombinant protein doses that included $80 / 40 \mu \mathrm{g}$ (first/second immunization); 60/30, 40/20; and 20/10 $\mu \mathrm{g}$. Emulsions were prepared by mixing protein fragments preparations in $200-400 \mu \mathrm{l}$ of PBS with an equal volume of Freunds adjuvant. Hamsters were immunized with a maximum of $200 \mu \mathrm{l}$ per injection site. A negative control group of hamsters were immunized with an emulsion of Freund's adjuvant and PBS. Pre and post-immunization serum samples were collected by phlebotomy of the retro-orbital venous plexus on the day before the first immunization and on the day before challenge, respectively. All animal studies were approved by the Committee for the Use of Experimental Animals of the Oswaldo Cruz Foundation.

\subsection{Recombinant Lig ELISA}

A preliminary checkerboard analysis was performed to identify the optimal antigen concentrations and dilutions of hamster sera and antibody conjugate for the recombinant Lig protein fragment ELISA. The final protocol was based on the following conditions. Microtitre plates (Costar) were coated with $100 \mathrm{ng}$ of recombinant Lig protein in $0.1 \mathrm{M}$ sodium carbonate buffer ( $\mathrm{pH} 9.6)$ at $4{ }^{\circ} \mathrm{C}$ overnight. The plates were washed three times with PBS, $0.05 \%$ Tween 20 (PBST), and incubated with $100 \mu$ of blocking buffer (PBST, 1\% BSA) at $37^{\circ} \mathrm{C}$ for $1 \mathrm{~h}$. After washing with PBST, wells were incubated with hamster serum, diluted 1:100 to 1:25,600 in blocking buffer, at $37^{\circ} \mathrm{C}$ for $1 \mathrm{~h}$. After washing three times with PBST, wells were incubated with rabbit anti-hamster IgG conjugated to horseradish peroxidase (Jackson Immunoresearch Laboratories), diluted $1: 25,000$, for $37^{\circ} \mathrm{C}$ for $1 \mathrm{~h}$. After a final cycle of washes (two times with PBST and one time with PBS), $100 \mu \mathrm{l}$ of 3,3',5,5'-tetramethylbenzidine (TMB) substrate was added to each well. The colour reaction was allowed to develop for $15 \mathrm{~min}$ and stopped with the addition of $25 \mu \mathrm{l}$ of $2 \mathrm{M} \mathrm{H}_{2} \mathrm{SO}_{4}$. Absorbance was determined at $450 \mathrm{~nm}$ with a microplate reader (Model 550, Bio-Rad). Mean values were calculated from serum samples assayed in duplicate. Each ELISA experiment was repeated three times. Geometric mean end-point titres (GMT) were determined by linear regression of the $\mathrm{OD}_{450}$ values from a serum titration to obtain a titre at the intersection with the background OD [38].

\subsection{Immunoblotting of native Lig proteins}

Late $\log$ phase cultures of L. interrogans Fiocruz L1130 were incubated in EMJH medium supplemented with $120 \mathrm{mM} \mathrm{NaCl}$ to induce LigA and LigB expression as previously described [39]. Leptospires were harvested, washed in PBS, resuspended in sample buffer and boiled for $10 \mathrm{~min}$ prior to SDS-PAGE analysis. Membranes of immunoblotted extracts were incubated with sera (diluted 1:200) from hamsters immunized with recombinant Lig proteins for $1 \mathrm{~h}$ at room temperature and after washing were incubated with Rabbit anti-hamster IgG secondary (diluted 1:5000; Sigma-Aldrich) for $1 \mathrm{~h}$ at room temperature. Membranes were incubated with goat anti-rabbit IgG conjugate (alkaline phosphatase; Jackson Immunoresearch Laboratories), diluted 1:10,000 for $1 \mathrm{~h}$ at room temperature and developed as described in Section 2.3.

\subsection{Hamster challenge studies}

Challenge experiments were performed with 9-week-old hamsters in groups of eight to determine the $50 \%$ lethal dose $\left(\mathrm{LD}_{50}\right)$ of L. interrogans Copenhageni Fiocruz L1-130. Hamsters were challenged with an inoculum of $10^{0}-10^{5}$ leptospires, diluted in PBS and administered intraperitoneally. Hamsters were monitored three times a day during the 28 day post-challenge period and euthanized when clinical signs of terminal disease appeared. The $\mathrm{LD}_{50}$ was calculated by the method of Reed-Muench [40].

For vaccine protection experiments, groups of 6-10 hamsters, immunized according to protocols described in Section 2 , were challenged at age 7-9 weeks with an intraperitoneal administration of $10^{3}$ leptospires 7 days after the second immunization. Hamsters were monitored daily for clinical signs of leptospirosis and euthanized when clinical signs of terminal disease appeared. Surviving hamsters on day 28 post-challenge were euthanized. Blood, urine, kidney, lung and liver tissues were harvested for serological, culture, and histopathology studies. Sterilizing immunity was determined based on culture isolation of leptospires, identification of leptospirosis-associated pathology and histological detection of leptospires in tissues of surviving hamsters. Kidney tissue and blood samples were used to inoculate EMJH medium. Dark-field microscopy was performed during an 8 week incubation period to identify positive cultures. Tissue sections were stained with hematoxylin and eosin for evidence of interstitial nephritis, pulmonary haemorrhage and liver diffuse dissociation. Warthin-Starry silver staining was performed to identify leptospires in tissues [41].

A negative control group of hamsters were immunized with an emulsion of PBS and Freund's adjuvant and inoculated with a lethal inoculum dose of leptospires according to the same protocol as described for recombinant Lig proteinimmunized hamsters. A positive control group of hamsters were immunized with killed whole-leptospires. Washed pellets of cultures $L$. interrogans strain Fiocruz L1-130 were 
heat-inactivated $56^{\circ} \mathrm{C}$ for 20 min, resuspended in PBS and stored at $-20^{\circ} \mathrm{C}$ until use. Hamsters were immunized with a dose of $10^{9}$ inactivated leptospires on day 0 and day 14 and challenged on day 28.

\subsection{Statistical analysis}

The Student's $t$-test was used to determine significant differences between the geometric mean titres obtained in ELISA results. The Fisher Exact test and log-rank sum test were used to determine significant differences for mortality and survival, respectively, among the groups immunized with Lig protein fragments and the negative control group. The chi-squared test for trend was used to evaluate significant differences between hamster groups immunized with different doses in the immunoprotection experiments. All $P$ values were two-sided and a $P$ value of $<0.05$ was considered to indicate statistical significance. EpiInfo 6.04d (Centers for Disease Control and Prevention) and GraphPad Prism 4 software systems (GraphPad Software) were used to perform the statistical analyses.

\section{Results}

\subsection{Preparation of purified recombinant Lig proteins}

Three protein fragments were cloned and expressed comprising $90 \%$ and $60 \%$ of the entire LigA and LigB molecules, respectively (Fig. 1). The LigBrep construct spans the second to seventh Big repeat domains of the $\operatorname{Lig} \mathrm{A}$ and $\mathrm{LigB}$, a region of sequence identity between the two proteins. The LigANI construct spans the 7th to 13th Big repeat domains of the LigA molecule. The LigBNI construct spans the 7th to 12th Big repeat domains of the LigB molecule. The sequence identity between these two non-identical regions is $38 \%$. Cloning of three PCR products, corresponding to LigANI, LigBNI and LigBrep, in pET100-TOPO expression vector allowed for purification of 6-10 $\mathrm{mg}$ of His-tagged recombinant protein per litre of transformed E. coli host culture. However, the three Lig recombinant fragments were expressed as inclusion bodies and required denaturing conditions for purification, followed by prolonged stepwise dialysis to obtain soluble protein preparations. Protein fragment preparations were obtained which had over 95\% purity (Fig. 2A) and reacted with pooled leptospirosis patient sera in immunoblot analysis (Fig. 2B).

\subsection{Antibody response induced by immunization with recombinant Lig protein fragments}

Golden Syrian hamsters were immunized with the three Lig protein fragments in Freund's adjuvant. Sera obtained 7 days after the second immunization from LigANI and LigBNI-immunized hamsters demonstrated high titre binding to homologous recombinant Lig fragments in an ELISA (Fig. 3A and B). Absorbance values for immune sera were significantly greater than pre-immune sera at titres up to 1:25,600. Although immunization with LigBrep produced specific antibodies that recognized the homologous recombinant fragment, absorbance values for immune sera were not significantly greater than those of pre-immune sera for titres $>1: 1600$ (Fig. 3C). Absorbance values for serum samples from hamsters immunized with PBS and Freund's adjuvant were $<0.06$ when diluted 1:100 in ELISAs with the three recombinant fragments (data not shown). Immunization with a specific Lig fragment produced significant cross-reactive antibody responses against the other two fragments. GMTs ranged from 1:1600 to 1:25,600 in ELISAs that measured cross-reactive antibodies in sera from immunized hamster to heterologous Lig proteins (data not shown).

Recombinant protein-based ELISA analysis was performed with sera from hamsters immunized with the LigANI fragment to determine the duration of humoral immune response and the response conferred by a range of immunization doses (first/second doses: 20/10, 40/20 and 80/40 $\mu \mathrm{g}$,

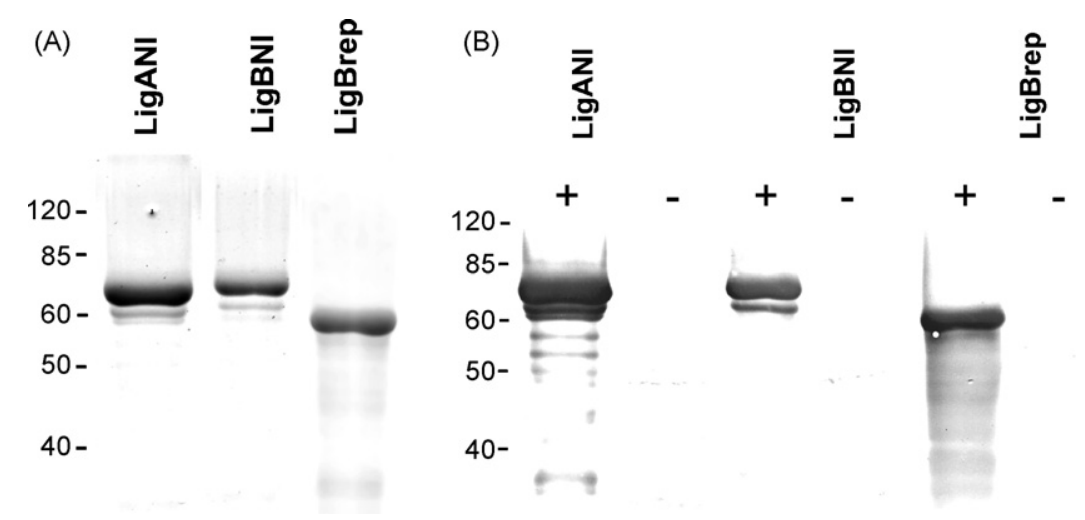

Fig. 2. Recombinant Lig proteins and seroreactivity with sera from leptospirosis patients. (A) Coomassie blue-stained SDS-PAGE gel of purified LigANI, LigBNI and LigBrep recombinant protein fragments (1.5 $\mu \mathrm{g} / \mathrm{lane})$. (B) Immunoblot analyses of LigANI, LigBNI and LigBrep recombinant protein fragments. Membranes were probed with pooled convalescent sera from leptospirosis patients $(+)$ and from healthy individuals ( - ). Positions of molecular mass markers $(\mathrm{kDa})$ are shown on the left. 

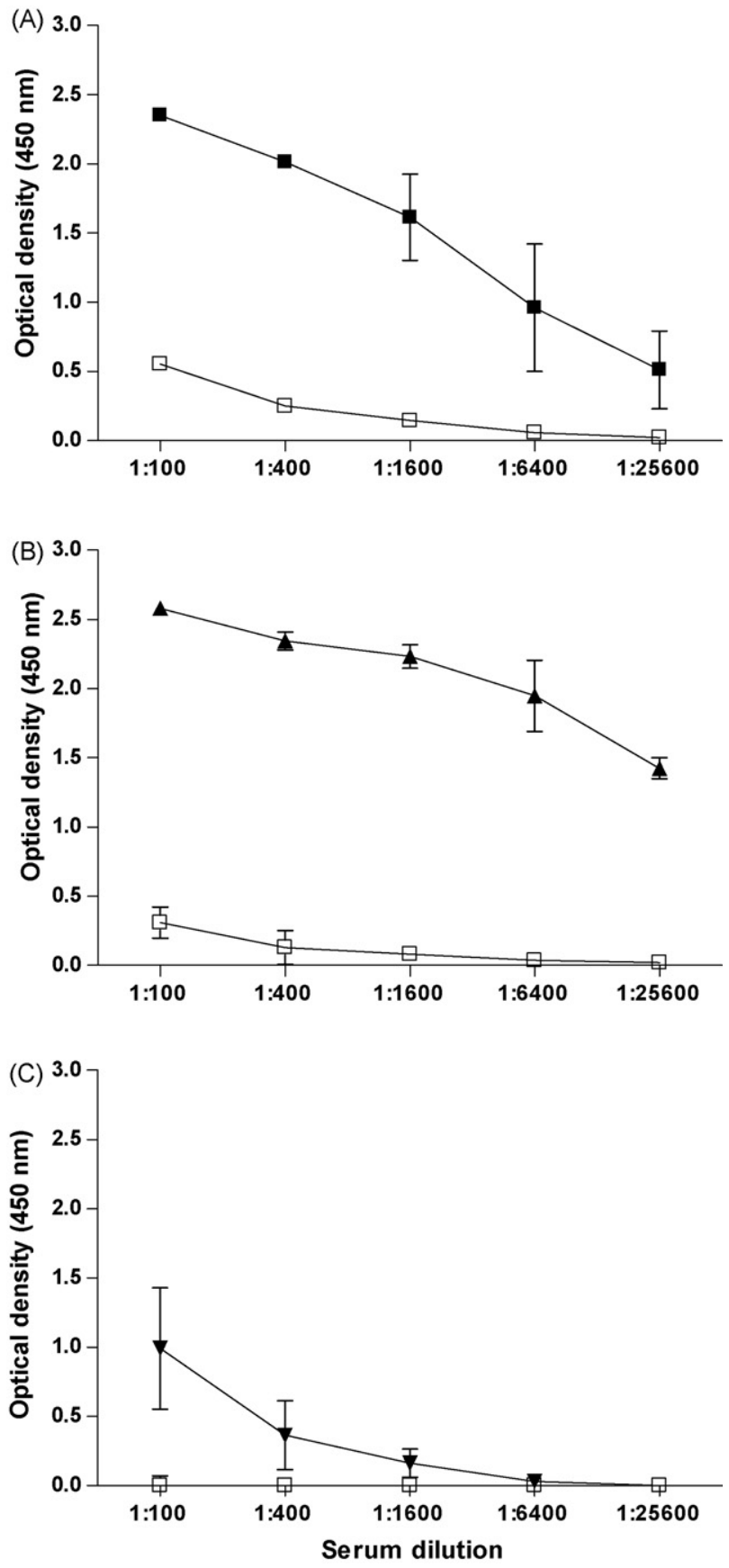

Fig. 3. Antibody responses in hamsters immunized with recombinant Lig proteins. ELISA reactions were performed to determine antibody levels against LigANI (A), LigBNI (B) and LigBrep (C) in sera from hamsters immunized with LigANI (A: pre-immune, $\square$; immune, $\square$ ) LigBNI (B: preimmune, $\square$; immune, $\boldsymbol{\Delta}$ ) and LigBrep (C: pre-immune, $\square$; immune, $\boldsymbol{\nabla}$ ). Mean absorbance (optical density, $450 \mathrm{~nm}$ ) \pm standard deviation (bars) are shown for a representative experiment among three that evaluated sera from groups of four immunized hamsters.

Fig. 4). Hamsters produced an antibody response with GMTs of 1:500-1:1500 one week after primary immunization with 20-80 $\mu \mathrm{g}$ of recombinant LigANI. GMTs peaked 1 week after the second immunization with 10-40 $\mu \mathrm{g}$ of recombinant LigANI (GMT range, 1:8000-1:29,000) and remained ele-

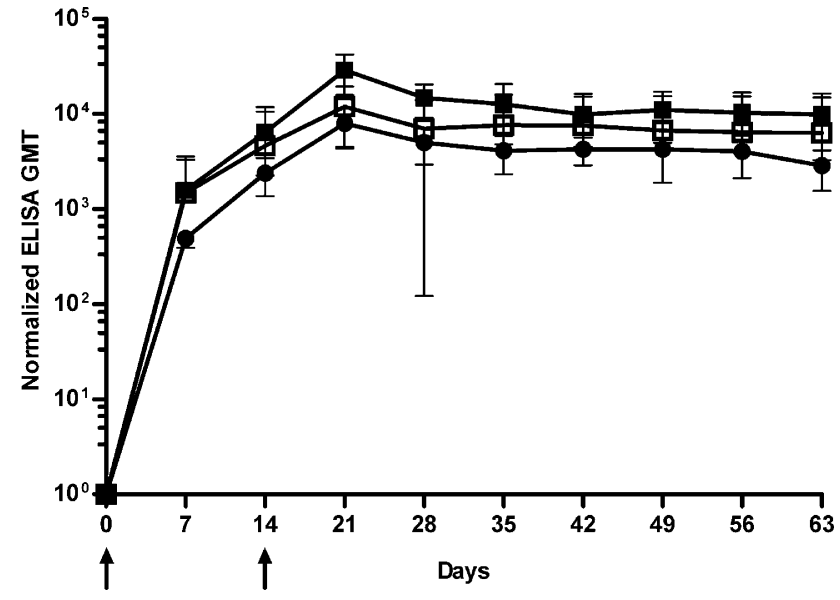

Fig. 4. Kinetics of IgG antibody response in hamsters immunized with recombinant LigANI protein fragment. ELISA was used to determine antiLigANI IgG antibody levels in hamsters immunized on day 0-14 (arrows) with LigANI doses of 80 and $40 \mu \mathrm{g}(\boldsymbol{\square}), 40$ and $20 \mu \mathrm{g}(\mathbf{O})$ and 20 and $10 \mu \mathrm{g}$ $(\square)$, respectively. Normalized geometric mean endpoint titres (GMTs) and standard deviation (bars) for sera collected from groups of four hamsters at weekly intervals over a 63 day follow-up period are shown.

vated (>1:3000) until the last observation point, 63 days after primary immunization. Of note, the standard deviation was large (1:4600-1:8700) for sera collected at the 28-day time point from hamsters immunized with $20 / 10 \mu \mathrm{g}$ of recombinant fragment due to high end-point titres in one animal (1:18,000). Immunization doses with $80 / 40 \mu \mathrm{g}$ (first/second immunization doses) produced significantly higher GMT at all time points in comparison to $40 / 20$ and $20 / 10 \mu \mathrm{g}$ immunization schemes.

\subsection{Immunization with recombinant Lig proteins induces antibodies that recognize native Lig proteins}

Immunoblot analysis of sera from groups of four hamsters found that immunization with each of the recombinant Lig proteins produced antibodies that recognize native Lig proteins in whole Leptospira lysates (Fig. 5). Sera from LigBrep immunized hamsters reacted with LigA and LigB proteins while sera from LigANI-immunized hamsters reacted specifically with LigA. Of note, sera from one of four LigBNI immunized hamsters recognized native $\operatorname{LigB}$, yet all reacted with native LigA.

\subsection{Determination of $L D_{50}$ for the L. interrogans challenge strain and characterization of the hamster infection model}

A series of four challenge experiments found that the mean $\mathrm{LD}_{50}$ for $L$. interrogans serovar Copenhageni strain Fiocruz L1-130 was $45.9( \pm 9.3)$ leptospires in 9-week-old hamsters (Table 1). Death occurred 10-18 days after challenge and occurred significantly earlier in groups that received higher challenge doses. A challenge dose of $10^{3}$ leptospires $(\sim 20 \times$ $\mathrm{LD}_{50}$ ) induced death in all hamsters, which occurred between 


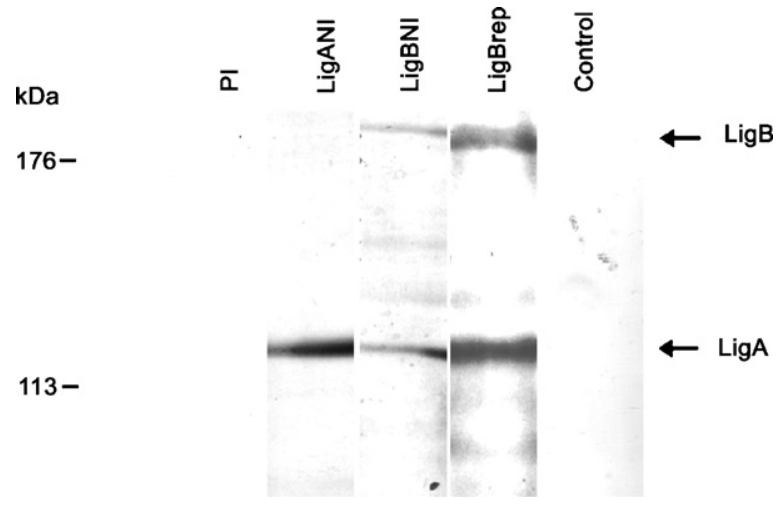

Fig. 5. Sera from hamsters immunized with recombinant Lig fragments recognize native LigA and LigB proteins. Immunoblots of whole-cell extracts of L. interrogans strain Fiocruz L1-130 (10 $0^{8}$ organisms per lane) were probed with representative samples of pre-immune (PI) and immune sera from hamsters immunized with LigANI, LigBNI, LigBrep and PBS (Control) with Freund's adjuvant. The mobility of molecular mass markers and expected positions of $\operatorname{LigA}(128 \mathrm{kDa})$ and $\operatorname{LigB}(201 \mathrm{kDa})$ are shown on the left and right side, respectively, of the figure.

the 10th and 18th day post-challenge (Fig. 5). Hamsters developed the characteristic clinical and histopathologic signs of leptospirosis. At the time of death, hamsters were jaundiced and demonstrated bleeding diatheses. Autopsies of infected hamsters found interstitial nephritis, acute damage of tubu- lar epithelia, marked dissociation of liver trabecula with hepatocytes presenting reactive changes such as cytoplasmic size variation, prominent nucleoli and binucleation, and pulmonary haemorrhage as primary pathological findings. Hamsters are a standard model used to evaluate protective immunity elicited by whole-cell vaccines [20]. Immunization with whole Leptospira-based preparations conferred protection $(100 \%)$ against lethal challenge $\left(10^{3}\right.$ leptospires) with the Fiocruz L1-130 strain (Table 2), indicating that the study's experimental model reproduced findings reported for established models of vaccine-based immunity.

\subsection{Protection conferred by immunization with recombinant Lig protein fragments}

Evaluation of recombinant Lig proteins in the hamster model of vaccine-induced immunity found that immunization with the LigANI fragment in Freund's adjuvant conferred protection against lethal challenge with $10^{3}$ leptospires $(20 \times$ $\mathrm{LD}_{50}$ ) (Fig. 6A and Table 2). Protection conferred with immunization of $80 / 40 \mu \mathrm{g}$ (first/second immunization dose) of LigANI ranged from $67 \%$ to $100 \%$ in the six experiments in which four different batches of recombinant protein were used. There were no significant differences between protection levels between these experiments. Immunization with

Table 1

Determination of the $\mathrm{LD}_{50}$ for L. interrogans strain Fiocruz L1-130 in the Golden Syrian hamster infection model

\begin{tabular}{|c|c|c|c|c|c|c|c|}
\hline \multirow[t]{2}{*}{ Experiment } & \multicolumn{6}{|c|}{ Challenge dose (no. leptospires) } & \multirow[t]{2}{*}{$\mathrm{LD}_{50} \mathrm{a}^{\mathrm{a}}$} \\
\hline & $10^{5}$ & $10^{4}$ & $10^{3}$ & $10^{2}$ & $10^{1}$ & $10^{0}$ & \\
\hline \multicolumn{8}{|c|}{ No. deaths per group $(n=8)$} \\
\hline 1 & 7 & 8 & 8 & 8 & $\mathrm{ND}^{\mathrm{b}}$ & ND & 36.5 \\
\hline 2 & 7 & 8 & 8 & 6 & ND & ND & 56.2 \\
\hline 3 & 8 & 7 & 8 & 5 & 3 & 0 & 39.8 \\
\hline 4 & 8 & 8 & 8 & 5 & 1 & 0 & 51.3 \\
\hline Mean \pm S.D. ${ }^{c}$ & & & & & & & $45.9 \pm 9.3$ \\
\hline
\end{tabular}

${ }^{\text {a }}$ Fifty percent lethal dose.

b Not determined.

${ }^{\mathrm{c}}$ Standard deviation.

Table 2

Protection conferred by immunization with recombinant Lig protein fragments against lethal challenge in the hamster model

\begin{tabular}{|c|c|c|c|c|c|c|}
\hline \multirow[t]{2}{*}{ Experiment } & \multirow{2}{*}{$\begin{array}{l}\text { First/second } \\
\text { immunization dose }(\mu \mathrm{g})\end{array}$} & \multicolumn{5}{|c|}{$\%$ Protection (no. survivors/total) } \\
\hline & & LigANI & LigBNI & LigBrep & Whole-cell preparation $^{\mathrm{a}}$ & Control immunization $^{\mathrm{b}}$ \\
\hline 1 & $80 / 40$ & $80.0(8 / 10)^{\mathrm{c}}$ & $10.0(1 / 10)$ & $0(0 / 10)$ & $100(4 / 4)^{\mathrm{c}}$ & $-(0 / 10)$ \\
\hline 2 & $80 / 40$ & $88.9(8 / 9)^{\mathrm{c}}$ & $0(0 / 9)$ & $\mathrm{ND}^{\mathrm{d}}$ & $100(4 / 4)^{c}$ & $-(0 / 9)$ \\
\hline 3 & $80 / 40$ & $66.7(6 / 9)^{\mathrm{c}}$ & $22.2(2 / 9)$ & ND & ND & $-(0 / 9)$ \\
\hline 4 & $80 / 40$ & $83.3(5 / 6)^{\mathrm{c}}$ & ND & ND & ND & $-(0 / 6)$ \\
\hline 5 & $80 / 40$ & $70.0(7 / 10)^{\mathrm{c}}$ & ND & ND & ND & $-(0 / 10)$ \\
\hline \multirow[t]{4}{*}{6} & $80 / 40$ & $100(8 / 8)^{\mathrm{c}}$ & ND & ND & ND & $-(0 / 8)$ \\
\hline & $60 / 30$ & $75.0(6 / 8)^{\mathrm{c}}$ & ND & ND & ND & $-(0 / 8)$ \\
\hline & $40 / 20$ & $87.5(7 / 8)^{\mathrm{c}}$ & ND & ND & ND & $-(0 / 8)$ \\
\hline & $20 / 10$ & $62.5(5 / 8)^{\mathrm{c}}$ & ND & ND & ND & $-(0 / 8)$ \\
\hline
\end{tabular}

\footnotetext{
a Immunizations were performed with heat-inactivated preparations of L. interrogans strain Fiocruz L1-130.

b Control immunizations were performed by administering PBS with Freund's adjuvant.

${ }^{c}$ Protection against lethal challenge was statistically significant $(P<0.05)$.

d Not determined.
} 
the LigBrep and LigBNI fragments did not induce protection with respect to either mortality or survival.

LigANI-immunized hamsters did not show clinical evidence of infection during the 28 day follow-up period after challenge infection. Although autopsy examination did not find macroscopic or histological evidence for disease in LigANI immunized hamsters that survived lethal challenge and were sacrificed 28 days post-challenge infection, leptospires were isolated and/or detected in kidney tissues. In contrast, leptospires were not isolated and/or detected in tissues of hamsters immunized with whole Leptospira preparations and infected with a lethal dose of leptospires, indicating that the whole-cell vaccine conferred sterile immunity.

Immunization regimens with lower doses (first/second doses: 20/10, 40/20 and 60/30 $\mu \mathrm{g}$ ) of LigANI fragment conferred a level of protection (63-88\%) against lethal challenge similar to the initial $80 / 40 \mu \mathrm{g}$ regimen (Table 2). The level of vaccine-induced protection was not significantly different between groups immunized with different immunization doses. Among LigANI-immunized hamsters that died after
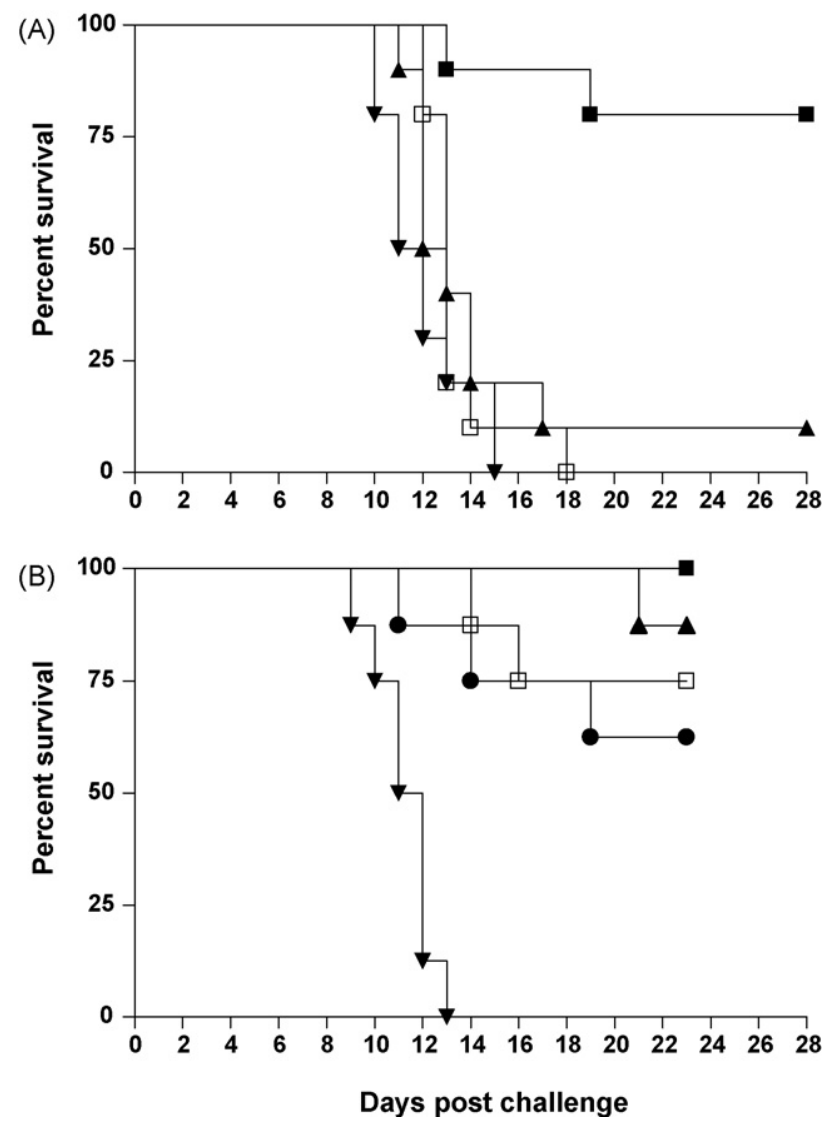

Fig. 6. Survival of hamsters immunized with recombinant Lig proteins after lethal challenge. (A) Post-challenge survival is shown for a representative vaccine evaluation (Experiment 1, Table 2) in which hamsters were immunized on day $21(80 \mu \mathrm{g})$ and day $7(40 \mu \mathrm{g})$ with $\operatorname{LigANI}(\boldsymbol{\square}), \operatorname{LigBNI}(\boldsymbol{\Delta})$, LigBrep $(\square)$ and PBS ( $\mathbf{\nabla})$ and challenged with L. interrogans strain Fiocruz L1-130 on day 0. (B) Protective effect conferred by immunization with increasing LigANI doses $(80 / 40 \mu \mathrm{g}, \mathbf{\square} ; 60 / 30 \mu \mathrm{g}, \square ; 40 / 20 \mu \mathrm{g}, \boldsymbol{\Delta} ; 20 / 10 \mu \mathrm{g}$, ; and $0 / 0 \mu \mathrm{g}, \boldsymbol{\nabla}$ ) on post-challenge survival (Experiment 6 , Table 2). lethal infection, death occurred significantly later than for the control group that received a lethal challenge dose (Fig. 6B).

Pre-challenge sera were analyzed from randomly selected LigANI-immunized hamsters in the six experiments (Table 2) to determine whether differences in antibody responses correlated with outcome after lethal challenge. All pre-challenge sera from LigANI-immunized hamsters recognized native LigA protein in immunoblot analysis of whole Leptospira extracts, regardless of the outcome. In recombinant LigANIbased ELISA, mean GMTs of pre-challenge sera (1:8000) from hamsters that died were lower, albeit not significantly different, than the mean GMTs $(1: 17,000)$ of sera from surviving hamsters.

\section{Discussion}

We have previously shown that Lig proteins are surfaceexposed outer membrane proteins of virulent leptospires [30] and therefore potential targets of a protective immune response. Previous studies examined the ability of Lig proteins to confer immunoprotection, yet the conclusions that could be drawn were limited because of the animal models and low virulence of the challenge strains used. Kozumi et al. demonstrated that immunization with recombinant fulllength $\mathrm{LigA}$ and truncated $\mathrm{LigB}$ proteins protected $\mathrm{C} 3 \mathrm{H} / \mathrm{HeJ}$ mice against lethal infection [29]. These findings were the first to suggest that Lig proteins are immunoprotective moieties. However, the mouse is not an ideal animal model of leptospirosis because it is relatively resistant to challenge with pathogenic Leptospira strains and requires a high inoculum $\left(>10^{6}\right.$ bacteria) to produce lethal infection $[42,43]$. Palaniappan et al. used hamsters, an accepted model for leptospirosis, to evaluate LigA protein-induced immunoprotection but did not demonstrate a significant difference in survival between LigA and control-immunized animals in independent experiments due to low mortality rates (12-43\%) among control-immunized animals [35].

In this study, we evaluated a panel of recombinant Lig protein fragments in the hamster infection model and found that the carboxy-terminal region unique to the $\operatorname{LigA}$ protein (LigANI) contained an immunoprotective domain. Fiocruz L1-130, a highly virulent strain of $L$. interrogans serovar Copenhageni was used for which a low inoculum dose $\left(10^{3}\right.$ bacteria, $\left.20 \times \mathrm{LD}_{50}\right)$ reproducibly induced characteristic disease manifestations and death in all control-immunized animals. LigANI conferred an average level of vaccine efficacy (Table 2) which is the highest reported for a subunit vaccine in the hamster model.

This study provides evidence that a single purified recombinant protein is able to induce protective immunity against lethal challenge in the standard hamster model of leptospirosis. Previous studies using purified recombinant proteins, including OmpL1, LipL41 and LipL32 [26,27], did not demonstrate immunoprotection in hamsters, even though these proteins have been shown to contain immunoprotec- 
tive epitopes using other approaches [27,28]. Evidence for LipL32 as a protective antigen comes from studies involving immunization with recombinant adenovirus [26] and naked plasmid DNA constructs [28]. The most likely explanation for the lack of an immunoprotective effect with recombinant proteins is the failure of the proteins to fold correctly and recapitulate their native secondary structure. Structural modelling of Lig molecules predicts that the repeat domains have a highly folded $\beta$-immunoglobulin sandwich structure [30]. Lig protein fragments used in this study were purified under denaturing conditions ( $8 \mathrm{M}$ urea), and allowed to renature gradually through a stepwise dialysis method of urea removal. This approach may have led to the correct refolding of some but not all of the critical conformational epitopes present in the Lig molecules, indicating a need for further refinement of the recombinant protein preparation protocol.

The mechanism of LigANI vaccine-mediated immunity remains speculative at this point. Immunization with LigANI produced robust antibody responses to recombinant and native protein at the time at which animals were challenged. Since LigA is a surface-exposed moiety, anti-LigA antibodies may have bactericidal or opsonophagocytic activity. Of note, the carboxy-terminal unique repeat domain region of LigA (LigANI) and LigB (LigBNI) has recently been shown to have fibronectin binding activity [33]. Anti-LigANI antibodies may therefore conceivably block key pathogen-host cell interactions in disease pathogenesis.

In this study, anti-recombinant LigA antibody titres were lower in pre-challenge sera from LigANI-immunized hamsters that died in comparison to those that survived after lethal infection, although this difference was not significant. We interpret this result as an indication that the recombinant LigA protein fragment used to immunize hamsters contains both protective and non-protective epitopes. Elucidation of the role of the anti-LigA antibody response requires determination whether protective immunity can be passively transferred. Alternatively, LigA may induce protective cellmediated responses as has been observed with whole-cell vaccines in cattle [44]. Of note, computational analyses found that LigA contains predicted T-cell epitopes [45].

Whole-cell inactivated leptospiral vaccines were developed by Ido and colleagues in the early 20th century [46] and have widespread commercial availability for livestock and companion animals. These whole-cell vaccines provide serovar-specific protection against accidental infection $[4,13]$. The lack of serovar cross-protection, the need for annual or biannual revaccination, and a high frequency of side effects are serious disadvantages that have limited the availability of whole-cell Leptospira vaccines for human use. A well-defined subunit vaccine composed of a cross-protective antigen that results in long-term immunity would be of great interest in the prevention of human leptospirosis.

Several challenges remain to be addressed to develop a subunit vaccine based on recombinant Lig proteins. In this study, immunizations were performed with Freund's adjuvant. The efficacy of Lig protein formulations must be determined using adjuvants acceptable for human use, such as aluminium hydroxide. An ideal recombinant proteinbased vaccine formulation would comprise a single fragment that confers cross-protective immunity against infection with heterologous serovars. Full-length ligA gene sequences have been identified in a range of $L$. interrogans and $L$. kirschneri serovars [29-32,36]. The predicted amino acid sequence homology is $80-97 \%$ for LigA proteins from these serovars [30]. Although ligA was not identified in the genome sequences of $L$. borgpetersenii serovar Hardjo [47] and $L$. interrogans serovar Lai [48], individual Big domains in LigA and LigB proteins share an amino acid sequence identity of $17-99 \%$ with each other. In this study, immunization with the LigANI fragment produced cross-reactive antibody responses against LigBrep and LigBNI fragments, which in turn may have contributed to the protective immunity observed in the hamster trials. In summary, we have shown that a recombinant protein fragment of the putative virulence determinant, LigA, reproducibly conferred high-level protection against lethal infection in the hamster model for leptospirosis. These findings provide proof-of-concept evidence for the feasibility of developing a subunit vaccine for human leptospirosis.

\section{Acknowledgements}

This work was supported by the Brazilian National Research Council (grants 300861/1996, 01.06.0298.00 and 420067/2005, and 554788/2006); Bio-Manguinhos, Oswaldo Cruz Foundation, Brazilian Ministry of Health (grant 09224-7); VA Medical Research Funds; the National Institute of Allergy and Infectious Diseases (grants AI052473 and AI034431) and Fogarty International Centre (grant TW00919).

\section{References}

[1] Levett PN. Leptospirosis. Clin Microbiol Rev 2001;14(2):296-326.

[2] World Health Organization. Leptospirosis worldwide, 1999. Wkly Epidemiol Rec 1999;74(29):237-42.

[3] Bharti AR, Nally JE, Ricaldi JN, Matthias MA, Diaz MM, Lovett MA, et al. Leptospirosis: a zoonotic disease of global importance. Lancet Infect Dis 2003;3(12):757-71.

[4] Faine SB, Adler B, Bolin C. Perolat P. Leptospira and leptospirosis. 2nd ed. Melbourne, Australia: MediSci; 1999.

[5] Farr RW. Leptospirosis. Clin Infect Dis 1995;21(1):1-8.

[6] Morgan J, Bornstein SL, Karpati AM, Bruce M, Bolin CA, Austin $\mathrm{CC}$, et al. Outbreak of leptospirosis among triathlon participants and community residents in Springfield, Illinois, 1998. Clin Infect Dis 2002;34(12):1593-9.

[7] Centres for Disease Control and Prevention. Outbreak of acute febrile illness among participants in EcoChallenge Sabah 2000-Malaysia, 2000. JAMA 2000;284(13):1646.

[8] Sejvar J, Bancroft E, Winthrop K, Bettinger J, Bajani M, Bragg S, et al. Leptospirosis in "Eco-Challenge" athletes, Malaysian Borneo, 2000. Emerg Infect Dis 2003;9(6):702-7. 
[9] Haake DA, Dundoo M, Cader R, Kubak BM, Hartskeerl RA, Sejvar JJ, et al. Leptospirosis, water sports, and chemoprophylaxis. Clin Infect Dis 2002;34(9):e3-40.

[10] Ricaldi JN, Vinetz JM. Leptospirosis in the tropics and in travelers. Curr Infect Dis Rep 2006;8(1):51-8.

[11] Meites E, Jay MT, Deresinski S, Shieh WJ, Zaki SR, Tompkins L, et al. Reemerging leptospirosis, California. Emerg Infect Dis 2004;10(3):406-12.

[12] Vinetz JM, Glass GE, Flexner CE, Mueller P, Kaslow DC. Sporadic urban leptospirosis. Ann Intern Med 1996;125(10):794-8.

[13] McBride AJ, Athanazio DA, Reis MG, Ko AI. Leptospirosis. Curr Opin Infect Dis 2005;18(5):376-86.

[14] Ko AI, Galvao Reis M, Ribeiro Dourado CM, Johnson Jr WD, Riley LW. Urban epidemic of severe leptospirosis in Brazil. Lancet 1999;354(9181):820-5.

[15] Sarkar U, Nascimento SF, Barbosa R, Martins R, Nuevo H, Kalafanos I, et al. Population-based case-control investigation of risk factors for leptospirosis during an urban epidemic. Am J Trop Med Hyg 2002;66(5):605-10.

[16] Johnson MA, Smith H, Joeph P, Gilman RH, Bautista CT, Campos KJ, et al. Environmental exposure and leptospirosis, Peru. Emerg Infect Dis 2004;10(6):1016-22.

[17] Hotez PJ, Ferris MT. The antipoverty vaccines. Vaccine 2006;24(31-32):5787-99.

[18] Moore GE, Guptill LF, Glickman NW, Caldanaro RJ, Aucoin D, Glickman LT. Canine leptospirosis, United States, 2002-2004. Emerg Infect Dis 2006;12(3):501-3.

[19] Adler B, Faine S. Immunogenicity of boiled compared with formalized leptospiral vaccines in rabbits, hamsters and humans. J Hyg (Lond) 1980;84(1):1-10.

[20] Freudenstein H, Hein B. Potency of leptospiral vaccines and protection against chronic infection in golden hamsters. Comp Immunol Microbiol Infect Dis 1991;14(3):229-34.

[21] Thiermann AB. Leptospirosis: current developments and trends. J Am Vet Med Assoc 1984;184(6):722-5.

[22] Sonrier C, Branger C, Michel V, Ruvoen-Clouet N, Ganiere JP, AndreFontaine G. Evidence of cross-protection within Leptospira interrogans in an experimental model. Vaccine 2000;19(1):86-94.

[23] Bolin CA, Zuerner RL, Trueba G. Effect of vaccination with a pentavalent leptospiral vaccine containing Leptospira interrogans serovar hardjo type hardjo-bovis on type hardjo-bovis infection of cattle. Am J Vet Res 1989;50(12):2004-8.

[24] Midwinter A, Faine S, Adler B. Vaccination of mice with lipopolysaccharide (LPS) and LPS-derived immuno-conjugates from Leptospira interrogans. J Med Microbiol 1990;33(3):199-204.

[25] Cullen PA, Haake DA, Adler B. Outer membrane proteins of pathogenic spirochetes. FEMS Microbiol Rev 2004;28(3):291-318.

[26] Branger C, Sonrier C, Chatrenet B, Klonjkowski B, Ruvoen-Clouet N, Aubert A, et al. Identification of the hemolysis-associated protein 1 as a cross-protective immunogen of Leptospira interrogans by adenovirusmediated vaccination. Infect Immun 2001;69(11):6831-8.

[27] Haake DA, Mazel MK, McCoy AM, Milward F, Chao G, Matsunaga J, et al. Leptospiral outer membrane proteins OmpL1 and LipL41 exhibit synergistic immunoprotection. Infect Immun 1999;67(12):6572-82.

[28] Branger C, Chatrenet B, Gauvrit A, Aviat F, Aubert A, Bach JM, et al. Protection against Leptospira interrogans sensu lato challenge by DNA immunization with the gene encoding hemolysin-associated protein 1 . Infect Immun 2005;73(7):4062-9.

[29] Koizumi N, Watanabe H. Leptospiral immunoglobulin-like proteins elicit protective immunity. Vaccine 2004;22(11-12):1545-52.

[30] Matsunaga J, Barocchi MA, Croda J, Young TA, Sanchez Y, Siqueira I, et al. Pathogenic Leptospira species express surface-exposed proteins belonging to the bacterial immunoglobulin superfamily. Mol Microbiol 2003;49(4):929-45.

[31] Palaniappan RU, Chang YF, Jusuf SS, Artiushin S, Timoney JF, McDonough SP, et al. Cloning and molecular characterization of an immunogenic LigA protein of Leptospira interrogans. Infect Immun 2002;70(11):5924-30.

[32] Palaniappan RU, Chang YF, Hassan F, McDonough SP, Pough M, Barr SC, et al. Expression of leptospiral immunoglobulin-like protein by Leptospira interrogans and evaluation of its diagnostic potential in a kinetic ELISA. J Med Microbiol 2004;53(10):975-84.

[33] Choy HA, Kelley MM, Chen TL, Moller AK, Matsunaga J, Haake DA. Physiological osmotic induction of Leptospira interrogans adhesion: LigA and LigB bind extracellular matrix proteins and fibrinogen. Infect Immun 2007;75(5):2441-50.

[34] Viriyakosol S, Matthias MA, Swancutt MA, Kirkland TN, Vinetz JM. Toll-like receptor 4 protects against lethal Leptospira interrogans serovar icterohaemorrhagiae infection and contributes to in vivo control of leptospiral burden. Infect Immun 2006;74(2):887-95.

[35] Palaniappan RU, McDonough SP, Divers TJ, Chen CS, Pan MJ, Matsumoto $\mathrm{M}$, et al. Immunoprotection of recombinant leptospiral immunoglobulin-like protein A against Leptospira interrogans serovar Pomona infection. Infect Immun 2006;74(3):1745-50.

[36] Nascimento AL, Ko AI, Martins EA, Monteiro-Vitorello CB, Ho PL, Haake DA, et al. Comparative genomics of two Leptospira interrogans serovars reveals novel insights into physiology and pathogenesis. J Bacteriol 2004;186(7):2164-72.

[37] World Health Organization. Human leptospirosis: guidance for diagnosis, surveillance and control. Malta: World Health Organization; 2003.

[38] Crowther JR. ELISA. Theory and practice. Methods Mol Biol 1995;42:1-218.

[39] Matsunaga J, Sanchez Y, Xu X, Haake DA, Osmolarity. a key environmental signal controlling expression of leptospiral proteins $\operatorname{LigA}$ and $\operatorname{LigB}$ and the extracellular release of LigA. Infect Immun 2005;73(1):70-8.

[40] Reed LJ, Muench H. A simple method of estimating fifty percent endpoints. Am J Hyg 1938;27:493-7.

[41] Chappel RJ, Prime RW, Millar BD, Mead LJ, Jones RT, Adler B. Comparison of diagnostic procedures for porcine leptospirosis. Vet Microbiol 1992;30(2-3):151-63.

[42] Adler B, Faine S. Susceptibility of mice treated with cyclophosphamide to lethal infection with Leptospira interrogans Serovar pomona. Infect Immun 1976;14(3):703-8.

[43] Adler B, Faine S. Host immunological mechanisms in the resistance of mice to leptospiral infections. Infect Immun 1977;17(1):67-72.

[44] Naiman BM, Blumerman S, Alt D, Bolin CA, Brown R, Zuerner R, et al. Evaluation of type 1 immune response in naive and vaccinated animals following challenge with Leptospira borgpetersenii serovar Hardjo: involvement of WC1(+) gammadelta and CD4 T cells. Infect Immun 2002;70(11):6147-57.

[45] Wiwanitkit V. Predicted epitopes of Lig A of Leptospira interrogans by bioinformatics method: a clue for further vaccine development. Vaccine 2007;25(15):2768-70.

[46] Ido Y, Hoki R, Ito H, Wani H. The prohylaxis of Weil's disease (Spirochaetosis icterohaemorrhagica). J Exp Med 1916;24:47183.

[47] Bulach DM, Zuerner RL, Wilson P, Seemann T, McGrath A, Cullen PA, et al. Genome reduction in Leptospira borgpetersenii reflects limited transmission potential. Proc Natl Acad Sci USA 2006;103(39):14560-5.

[48] Ren SX, Fu G, Jiang XG, Zeng R, Miao YG, Xu H, et al. Unique physiological and pathogenic features of Leptospira interrogans revealed by whole-genome sequencing. Nature 2003;422(6934):888-93. 